\title{
Assessment of regional and global left ventricular function with electromechanical mapping: validation against MRI. A PRECISE substudy
}

\author{
Esther Pérez-David“, Ricardo Sanz-Ruiz, Raquel Yotti, Javier Bermejo, Maria Eugenia Fernandez Santos, \\ Fernando Sarnago Cebada, Jaime Elizaga Corrales, Francisco Fernandez Avilés
}

From 18th Annual SCMR Scientific Sessions

Nice, France. 4-7 February 2015

\section{Background}

Electromechanical mapping (EMM) of the left ventricle (LV) provides voltage and contractility information of the LV (based on linear local shortening, LLS). Although EMM parameters show excellent correlation with viability data by MRI, little information is available regarding performance of EMM for assessment of regional and global LV function. The purposes of our study were: a) to study the relationship between EMM (LLS) and wall motion by MRI in all segments and b) to correlate LV volumes and LVEF with both techniques.

\section{Methods}

The PRECISE clinical trial of freshly isolated adiposederived stem cells for angiogenesis included pts with chronic stable CAD, reversible perfusion defects detectable by SPECT and not amenable for revascularization. This study was a post-hoc analysis of the baseline and 6-month follow-up data of EMM and MRI parameters corresponding to the $22 \mathrm{p}$ of the PRECISE trial that were enrolled in our center. EMM was performed with the NOGA XP system. MRI studies were performed with a $1.5 \mathrm{~T}$ scanner (Philips Inter ${ }^{\circledR}$, The Netherlands) and included cine imaging, first-pass perfusion and late enhancement. EMM and MRI were performed and analyzed by independent observers, blinded to the results of the other technique. MRI variables included: regional wall motion score (normal=1; hypokinetic $=2$; akinetic $=3$ ), LV volumes and LVEF. EMM variables included LLS (\%) for every segment, LV volumes and LVEF.

\section{Results}

Segments with better WMS by MRI had significantly higher values of LLS parameters (Figure, left). Regarding global left ventricular function parameters, agreement between NOGA XP and MRI ventricular parameters was
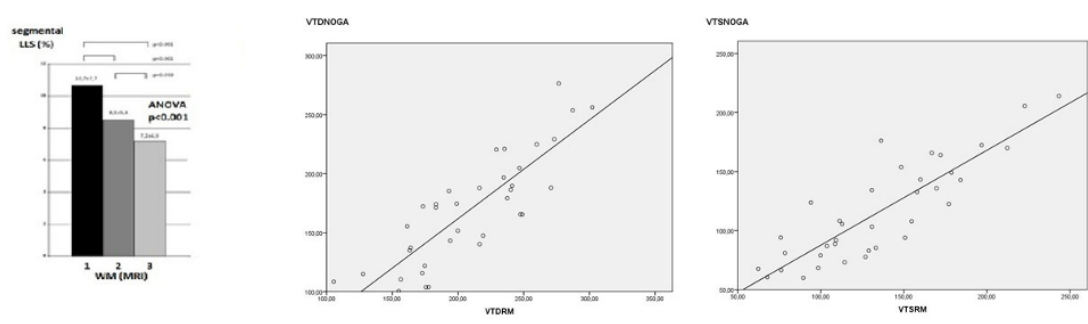

Figure 1

\footnotetext{
Cardiology, Hospital Gregorio Marañón, Madrid, Spain
} 
good (Figure: center and right graphs): ICC $=0.85$ (IC 95\% 0.72-0.92), $\mathrm{r}=0.86$ (IC 95\% 0.79-0.93) and $\mathrm{r}=0.66$ (IC 95\% 0.43-0.81) for LVEDV, LVESV and LVEF respectively. Volumes were slightly underestimated with NOGA compared to MRI (mean difference: $39 \pm 26 \mathrm{cc}$ for LVEDV and $19 \pm 23$ cc for LVESV).

\section{Conclusions}

We show for the first time a good agreement in terms of regional wall motion, LV volumes and ejection fraction between EMM and cardiac MRI.

\section{Funding}

No funding to report.

Published: 3 February 2015

doi:10.1186/1532-429X-17-S1-P143

Cite this article as: Pérez-David et al:: Assessment of regional and global

left ventricular function with electromechanical mapping: validation

against MRI. A PRECISE substudy. Journal of Cardiovascular Magnetic

Resonance 2015 17(Suppl 1):P143.

Submit your next manuscript to BioMed Central and take full advantage of:

- Convenient online submission

- Thorough peer review

- No space constraints or color figure charges

- Immediate publication on acceptance

- Inclusion in PubMed, CAS, Scopus and Google Scholar

- Research which is freely available for redistribution

Submit your manuscript at www.biomedcentral.com/submit
C Biomed Central 